\title{
LOS ESTUDIOS SOBRE EL DICCIONARIO (1984-1993)
}

Francisco Abad

$U N E D$

\section{A la memoria de Manuel Taboada y de Victor Siurana}

En estos últimos años han aparecido varios volúmenes -recopiladores todos ellos de artículos y escritos previos-, dedicados a cuestiones de lexicografía española: estudian en efecto problemas en torno a los Diccionarios del español. Se trata de los libros de Manuel Seco, Estudios de lexicografía española (Madrid, Paraninfo, 1987), de Rafael Lapesa Léxico e historia. Diccionarios (Madrid, Istmo, 1992), de Manuel Alvar, La lengua de... (Universidad de Alcalá de Henares, 1993), y de Manuel Alvar Ezquerra, Lexicografia descriptiva (Barcelona, Biblograf, 1993); tampoco han faltado artículos de revista que contribuyen a precisar los hechos, como el de Pedro Álvarez de Miranda, «En torno al Diccionario de Terreros», del Bulletin Hispanique (94/2, 1992).

Sin salir de los presentes estudiosos contamos asimismo con análisis suyos propiamente léxicos y no ya lexicográficos: $R$. Lapesa ha publicado varias preciosas monografías referidas al Romanticismo, y a Manuel Alvar le publicaron en Madison unos Estudios léxicos (1984), etc.

Nos proponemos repasar algunos de los contenidos de las anteriores obras, para al final proponer varias conclusiones. 
El volumen de Rafael Lapesa, Léxico e historia. Diccionarios, consta de siete capítulos más algunos apéndices. Entre esos escritos se encuentran:

\section{— «Los Diccionarios de la ACAdemia»}

Noticia de los trabajos preparatorios de la edición del Diccionario vulgar o común que saldría en 1970, y que inforra cómo «la Academia encomendó a don Vicente García de Diego la revisión de las etimologías, y a don Julio Casares todas las demás modificaciones».

Lapesa postula que el Diccionario común no debe ser un Diccionario de Madrid, sino "de todo el mundo hispánico», y en este sentido anuncia que «aparte de incluir nuevos americanismos, se han revisado muchas de las indicaciones sobre la extensión geográfica de los que ya figuraban en ediciones anteriores».

En cuanto a la inclusión de los tecnicismos nuestro autor estima que se deberá estar cerciorado de que han alcanzado un uso efectivo fuera de lo estrictamente profesional, hasta no ser raro tal uso en las personas cultas de otros ambientes.

Referido al Diccionario Histórico, Lapesa informa entonces cómo muerto Casares la dirección de la obra y del Seminario de Lexicografía «han pasado a don Vicente García de Diego".

\section{- «Colaboración de las Academias de la lengua al Diccionario HISTÓRICO»}

Escrito de 1956 en el que se mencionan los dos intentos académicos de llevar a cabo un Diccionario histórico de la lengua; este Diccionario «pretende recoger el vocabulario de todas las épocas y de todos los ambientes, desde el culto... hasta el plebeyo, desde el de área geográfica general hasta el exclusivo de un país o región, desde el duradero hasta el de vida efímera".

Lapesa pide que las Academias del mundo hispánico presten su ayuda «valiosísima» para calificar la estimación de las palabras (de uso general, colo- 
quial, vulgar, ...), para informar acerca de los eufemismos y de los disfemismos, etc.

— «INFORME RELATIVO AL DicCionaRio HISTÓRICO DE LA LENGUA ESPAÑOLA»

Estamos en 1960 y nuestro autor trata del intento de inventario - lo más completo posible- del léxico «acuñado por los pueblos de habla española en once siglos de historia» y en dos continentes.

Resultan pues «dos gigantescas dimensiones» (en el tiempo y en el espacio) que se tratan de abarcar; en el tiempo se arranca de los testimonios de la época preliteraria del idioma en «los siglos IX y X» y se llega hasta nuestros días. Estamos así -de hacia mitad del siglo IX hasta mitad del siglo XX- ante once siglos de documentación léxica.

En cuanto a la verticalidad sociocultural el Diccionario no se contenta con el vocabulario literario: «Hemos procurado registrar también el riquísimo caudal de voces populares, tanto de uso general como de áreas geográficas más o menos restringidas... En España [se incorporan] los regionalismos astur-leoneses y alto-aragoneses que no tengan fonemas ajenos al sistema castellano... y los regionalismos del castellano hablado en zonas bilingües. Para los americanismos y regionalismos americanos no ha habido problema de límites, y los indigenismos han entrado con sólo aparecer en contextos castellanos y ajustarse a la fonética de nuestra lengua».

— «El Diccionario histórico de La LENGUa española»

Informe aproximadamente contemporáneo del anterior, pero más amplio y sistemático; hasta su incorporación al presente volumen sólo se había publicado en lengua francesa.

Don Rafael repite cómo el Diccionario «pretende registrar el vocabulario de todas las épocas y de todos los niveles» según su diversa extensión geográfica en el mundo hispánico, y tanto haya tenido vigencia idiomática prolongada o efímera. 
Los diferentes tipos de palabras técnicas - propone- reclaman tratamiento distinto: «uno está constituido por la nomenclatura agrícola y ganadera, enraizada casi siempre en la más pura tradición de la lengua; el vocabulario de los viejos oficios, menos puro, no tiene una menor raigambre secular, lo mismo que el léxico de la ciencia y la náutica, de las artes y del derecho. En todos estos casos se impone una aceptación total. También habrá que admitir la terminología de la industria moderna, a pesar de su carácter extranjero».

Lapesa propugna una actitud sobria por lo que respecta a la tecnología científica, de manera que sólo entren en el Diccionario histórico «los términos que han pasado a la lengua general o son de empleo constante» en cada dominio.

- «ALMa Y ÁNIMA EN El DicCionaRio históRICO de la LENGUA ESPAÑOLA»

Nuestro autor hace una referencia general a los materiales que están siendo utilizados en el Diccionario histórico..., y testifica el sentido amplio en que se toman los textos literarios: efectivamente por obras literarias acoge el Diccionario «no sólo las de creación..., sino también las de crítica, filosofía, Historia, memorias y cartas, e incluso los ensayos científicos de divulgación».

Lapesa sistematiza el artículo alma tal como aparece en el Diccionario histórico... y explica que las acepciones de la palabra se encuentran repartidas en ocho series que significan «elemento del ser humano como principio inmaterial de su vida», «como superviviente a la muerte corporal», «como órgano de la afectividad» $\mathrm{y}$ «de las actividades intelectuales y religiosas»; además «vida, vivacidad, vigor», «el principio vital en entes no humanos», «sustancia, fundamento» $y$ «partes del cuerpo de diversos animales, etc.».

- «Alma y ánima en el Diccionario histórico de la lengua española: SU FRASEOLOGfA»

A propósito de esta fraseología nuestro autor comprueba cómo «las locuciones viven en variantes», $y$ así se rehacen en continua transformación acepta- 
da por un número más o menos amplio de hablantes. Otras perduran «en estado latente».

No estamos por tanto ante «frases hechas» que deben repetirse en su literalidad, sino que se trata de una vida oral en variantes, una parte de la cual vida llega a la escritura.

Rafael Lapesa aborda en su volumen cuestiones relativas al Diccionario común de la Academia, y asimismo otras referidas al Diccionario histórico. Respecto al primero postula que lo sea de la lengua de todo el mundo hispanohablante, y que en este sentido aporte los testimonios positivos que le sean posibles acerca de la vigencia respectiva de cada americanismo; por otra parte, el vocabulario técnico quedará recogido cuando su empleo no sea raro entre personas cultas.

El Diccionario histórico... trata a su vez de testimoniar los usos léxicos de más de once siglos, teniendo presentes todos los puntos de las dimensiones diacrónica, diatópica y diastrática del idioma. El vocabulario técnico ha de quedar recogido en este caso no sólo cuando no sea raro entre personas cultas, sino cuando ofrezca un empleo constante en su dominio respectivo. La lengua literaria que sirve de fuente al Diccionario comprende las obras propiamente poéticas y además los textos historiográficos, filosóficos, de divulgación científica,...

\section{* * *}

Manuel Seco es probablemente la persona de mayor preparación lexicográfica de entre nosotros; esa preparación no se improvisa, y tarda meses y años en madurar: sin duda él posee tal madurez. De los Estudios de lexicografía española destacamos ahora varios capítulos:

— «LOS DICCIONARIOS HISTÓRICOS»

Una idea general que enuncia nuestro autor es la de que todo diccionario posee naturaleza «de herramienta, y no de especulación científica»: se trata pues de algo idiomático y no enciclopédico. 
Corominas mantiene que su Diccionario crítico etimológico «tiene... el carácter de un diccionario histórico», y Seco se ve obligado a decir que es un «aserto bastante menos evidente para el lector que para el autor»: en efecto no se trata en verdad de tal obra, dado su esquematismo en cuanto a los hechos semánticos.

Diccionarios históricos son los dos iniciados por la Academia, aunque con diferencias: el de 1933 documentaba las acepciones, pero sin intentar la historia semántica de las palabras; el de 1960 «presenta con rigor cronológico la evolución semántica total de la palabra a lo largo de la historia de la lengua». Ocurre así que todo diccionario histórico «es prácticamente una gran suma alfabética de monografías históricas de las palabras», y desde luego constituye «la base documental indispensable para construir cualquier diccionario general de la lengua».

Seco subraya asimismo que el actual Diccionario histórico... de la Academia supone la empresa más ambiciosa que nunca se haya propuesto la Corporación.

\section{- «CUERVO Y LA LEXICOGRAFIA HISTÓRICA»}

En el presente escrito Manuel Seco precisa también cómo el Diccionario de Cuervo no es un diccionario histórico, sino de sintaxis, hecho que determina naturalmente la macroestructura de la obra al limitarla a las palabras concemidas por cuestiones de «construcción y régimen».

\section{— «El NACIMIENTO DE LA LEXICOGRAFÍA MODERNA NO ACADÉMICA»}

Brillante panorama que saca a luz y sistematiza el capítulo de la lexicografía no académica de 1842 a 1853 , es decir, en la década un poco larga en que asimismo se publican las ediciones novena y décima del Diccionario de la Academia. Salen entonces efectivamente los Diccionarios de Salvá, de Ramón Joaquín Domínguez, de José Caballero, de Chao,...

Dominguez amplía la macroestructura hasta llevarla a abarcar «todos los tecnicismos de las diversas actividades y saberes», e integra asimismo en ella nombres propios y desarrollos didácticos: en una y otra cosa seguía respectivamente los precedentes de Terreros y de Covarrubias, y al fundirlos en una sola obra alcanzo «la fundación entre nosotros del género diccionario enciclopédico». 
En la traza de Ramón Joaquín se publicó el Diccionario enciclopédico de la lengua española revisado por Eduardo Chao, obra en la que -como se advierte- la lengua es llamada ya «española».

Por su parte a Vicente Salvá ha de reconocerse el intento de tener en cuenta al español de América y de incluir por tanto los americanismos o «provincialismos de sus habitantes», según él decía.

En síntesis establece Manuel Seco que el conjunto de diccionarios de entre 1842 y 1853 aporta «una incorporación más abierta del léxico actual», y que destaca en ellos «la determinación de Salvá de dar entrada plena al español de América» (lo que no fue tomado en serio por otros hasta bastantes decenios después). Entre nosotros se aclimató además entonces «de la mano de Domínguez... el género diccionario enciclopédico».

\section{- «RAMÓN JOAQUIN DOḾNGUEZ»}

Manuel Seco estudia al autor de «el diccionario de nuestra lengua que más ediciones ha alcanzado después del de la Academia», e insiste en que por vez primera en nuestra cultura moderna «se incorpora dentro de la macroestructura de un diccionario de lengua una serie extensa de informaciones enciclopédicas».

— «MEDIO SIGLO DE LEXICOGRAFÍA ESPAÑOLA (1930-1980)»

Al aludir al Diccionario común o usual de la Academia nuestro autor hace estas indicaciones certeras: «Se hace sentir cada día más la necesidad de sustituir el sistema de parches sucesivos con que se han ido preparando las nuevas ediciones, por una revisión general que actualice el metalenguaje, resuelva las contradicciones y elimine las definiciones circulares».

- «EL PRIMER DICCIONARIO SINCRÓNICO DEL ESPAÑOL»

Informe sobre el Diccionario del español actual que prepara el autor junto con Gabino Ramos y Olimpia Andrés, y que se propone registrar el léxico del 
español general y también «el marcado o restringido» (culto, humorístico, literario, ...). Las voces técnicas tendrán cabida si «son usadas o al menos entendidas por el hablante no especialista».

En la microestructura este Diccionario procura cumplir la «ley de la sinonimia», aunque hay definiciones (palabras gramaticales, etc.) «que no pueden ser formuladas en metalengua de contenido —esto es, en forma sinonímica-, sino en metalengua de signo».

Seco piensa que los límites entre una definición nominal y una definición real marcan la frontera entre el diccionario y la enciclopedia.

Manuel Seco es quizá el español vivo que más papeletas lexicográficas ha tenido en su mano y las ha estudiado. Su experiencia nos hace ver que en sentido cierto, un Diccionario histórico de la lengua es sólo el que presenta de acuerdo con su cronología la evolución semántica total de las palabras. Por lo que se refiere al Diccionario académico usual recomienda que se eviten en el mismo las definiciones circulares, las contradicciones, etc., y que la definición lexicográfica tenga en cuenta que es «una información sobre todo el contenido y nada más que el contenido de la palabra definida». Además el definiente ha de poseer forma adecuada a la función sintáctica propia del definido.

Seco subraya asimismo la preocupación por los americanismos de Vicente Salvá, y la fundación que hace entre nosotros Ramón Joaquín Domínguez de los diccionarios enciclopédicos.

\section{* * *}

En el Prólogo de su volumen La lengua de... indica Manuel Alvar que aborda en el mismo «ciertas cuestiones lexicográficas»; aunque un autor es dueño de sus títulos, la obra podría haberse titulado acaso de manera más definida, y sin ir más lejos «Cuestiones lexicográficas». Veamos dos de los capítulos:

— «El CAMinar Del Diccionario aCADÉmico»

Se trata de un conjunto de comentarios en torno a la trayectoria de los Diccionarios de la Academia. Sin indicar los motivos que le llevan a ello, nuestro 
autor destaca los «criterios tan justos y seguros» con que fueron hechas las ediciones de $1803,1817,1822,1843,1889$ y 1925 del léxico oficial: sin duda hay una errata, y al hablar del Diccionario de 1889 se alude a otro. En todo caso importa que se llame la atención sobre el relieve respectivo de cada edición del léxico académico, pero deberemos conocer por qué; sólo de manera intuitiva e insegura sabemos hasta ahora algo de la historia interna de los Diccionarios de la Academia y sobre su importancia relativa. En el camino de esta deseable historia interna Alvar advierte además cómo en 1869 «se da un paso decisivo: se suprimen las correspondencias latinas». Del mismo modo encarece nuestro autor las novedades de la edición «décima quinta», manifestadas por los académicos en la "Advertencia» inicial y algunas de cuyas afirmaciones copiamos directamente: «Se han añadido gran número de acepciones y voces nuevas... Se han incluido muchas voces técnicas [y] ... la mayor parte del habla común de las personas ilustradas... [La Academia] ha concedido también atención muy especial a los regionalismos de España y de América que se usan entre la gente culta de cada país... El provincialismo de España encierra una riqueza léxica de inapreciable valor porque conserva viva gran porción de vocablos pertenecientes al antiguo fondo patrimonial de nuestro idioma. Y por su parte el americanismo sabido es cuántas voces hispánicas atesora que en la Península han caído en desuso total o parcial».

Manuel Alvar subraya asimismo que en 1970 la Academia se ha propuesto (copiamos de nuevo directamente del Diccionario de ese año) «el avance decidido hacia la definición directa objetiva».

\section{- «LOS DicCIONARIOS ACADÉMICOS Y EL PROBLEMA DE LOS NEOLOGISMOS»}

Para la incorporación de los neologismos nuestro autor se pronuncia así: «La existencia de dos diccionarios (los llamados de uso y manual) acaso faciliten una adopción progresiva: primero en el repertorio que no tiene valor normativo; después, si el neologismo resulta válido, en el común [...]. Ese repertorio no normativo habrá sido la antesala para acceder al Diccionario usual».

En particular para los tecnicismos científicos —entendemos que se refiere a ellos Alvar-, el criterio de adopción definitiva puede ser el de que quepan «en un manual de segunda enseñanza».

Manuel Alvar ha llamado la atención sobre un hecho de importancia: el relieve respectivo que posee cada edición del Diccionario académico; por su- 
puesto este hecho deberá ser tomado en cuanto nos informa y nos testimonia acerca del proceso de la historia de la lengua. Creemos con Manuel Alvar Ezquerra que «resta por comprobar cómo es por dentro cada una de las ediciones», y por nuestra parte insistimos en que esa comprobación no ha de limitarse sólo a lo historiográfico, sino que debe servir de testimonio sobre la evolución lingüística.

\section{***}

La consideración de los textos de los sucesivos Diccionarios académicos más la reflexión a partir de lo dicho por la bibliografía disponible nos lleva a varias conclusiones que proponemos directamente o que hacemos nuestras:

1. La definición semántica en los diccionarios ha de estar referida a la particular forma del contenido de cada palabra. «Si el enunciado definidor puede sustituir al término definido... sin que el sentido... se altere, el enunciado definidor es válido» (M. Seco).

2. Las palabras gramaticales y las interjecciones tienen que estar explicadas no obstante en «metalengua de signo» y no ya en la metalengua de contenido.

3. El Diccionario académico usual deberá hacerse cargo de los provincialismos españoles de «los dialectos específicamente castellanos» (M. Alvar).

4. Asimismo debe ofrecer testimonios positivos acerca de la extensión geográfica de los provincialismos.

5. El tecnicismo científico cabe en el diccionario cuando lo empleen o lo entiendan bachilleres superiores o personas cultas en general.

6. Tarea pendiente es la de analizar cada edición sucesiva del Diccionario común académico, y la de trazar conforme a ese análisis parte de la Historia de la lengua española moderna ${ }^{1}$.

7. Un Diccionario histórico es sólo propiamente el que ofrece de acuerdo con su cronología la evolución semántica total de cada palabra del idioma.

1 Sobre el abandono en que se encuentra el estudio de la historia de la lengua durante los siglos últimos y sobre las causas de que ello ocurra así y la necesidad de tal estudio, reflexionamos en el escrito «Hacia una Historia de la lengua española moderna», entregado en este momento para su publicación en la revista de la Universidad Complutense Didáctica, 6, 1994 [pp. 13 ss.]. 
8. La «lengua literaria» empleada como fuente del Diccionario histórico ha de ser entendida en tanto comprende no sólo los textos artísticos, sino asimismo los de filosofía, historiografía, de didáctica científica, etc.

9. En el caso de los diccionarios históricos los tecnicismos científicos o no, deben quedar recogidos si su uso resulta constante en el ámbito respectivo.

10. La historia de los Diccionarios académicos debe reconocer la impronta que en ella han marcado Julio Casares (1936-1964) y -a la vez que él y destacadamente después de él- Vicente García de Diego.

\section{* * *}

A manera de apéndice diremos que conocemos varios análisis léxicos que no están publicados, pues los hemos orientado y se han presentado como trabajos de curso en el doctorado o como Memorias de Licenciatura. Particularmente denso fue el estudio de Juan Antonio Cardete en torno a la «Historia de la palabra novela».

Corominas nada más anota escuetamente que novela procede «del it. novella» y significa «relato novelesco más bien corto» (DCECH, IV, 246b); por su parte Juan Antonio Cardete documenta cerca de veinte acepciones a lo largo de la historia del idioma, y analiza el desplazamiento semántico del vocablo desde el sentido central etimológico de «relato breve» hasta el de «relato extenso».

Algunas de las acepciones con que aparece el vocablo en castellano son por ejemplo:

a) «Relato transmitido oralmente» (Santillana).

b) «Relato escrito inserto en una obra literaria» (Juan Rodríguez del Padrón).

c) «Relato en verso» (siglos XVI y XIX).

d) «Roman» (ya en 1641, sobre todo desde el XIX). En efecto y según escribía don José Fernández Montesinos, «el concepto de novela... sólo en tiempos muy recientes ha llegado a comprender las obras de ficción extensas» ${ }^{2}$.

2 J. F. Montesinos: Introducción a una Historia de la novela en España en el siglo XIX, Madrid, $1983^{4}$, p. 139. 
e) En fin la edición decimonovena del Diccionario académico llama asimismo novela de modo figurado a los «hechos interesantes de la vida real que parecen ficción» ${ }^{3}$.

${ }^{3}$ Estas páginas son las primeras que podemos escribir en nuestro nuevo domicilio, ocho meses más tarde de que un siniestro grave nos dejase sin vivienda y sin biblioteca, y sin que todavía hayamos podido normalizar nuestra vida de trabajo. Distintos compañeros y amigos nos han mostrado con su palabra o sus hechos un testimonio de adhesion; en particular recordamos ahora la generosidad de José Luis Abellán, Rafael Lapesa, José Carlos Mainer y - sobre todo- Jose María Jover. 